\title{
PARA UM DEBATE ENTRE SUBJETIVIDADE E PENSAMENTO TÉCNICO- CIENTÍFICO EM DIÁLOGO COM ADORNO E HORKHEIMER ${ }^{1}$
}

\author{
Ermínio de Sousa Nascimento ${ }^{2}$ \\ José Edmar Lima Filho ${ }^{3}$
}

\begin{abstract}
Resumo:
O presente artigo considera a questão da subjetividade e do saber técnico-científico na perspectiva de Theodor W. Adorno (1903-1969) e Max Horkheimer (1895-1973), sobretudo no texto Dialética do Esclarecimento (1985), com o objetivo de identificar, baseado na crítica da concepção kantiana de esclarecimento, se é possível se ter a autonomia do sujeito conservando o saber técnico-científico como a única forma válida de conhecimento. O modus operandi desse saber, transmuta o sujeito pensante em operador técnico para produzir mercadoria na sociedade capitalista, convertendo autonomia em aperfeiçoamento técnico-produtivo. Com isso, homens e máquinas são unificados, tanto pela linguagem da ciência como na produção em série de mercadorias. A busca pela eficácia e utilidade do saber, ao invés de estimular o homem a se esforçar para fazer uso do seu entendimento por conta própria, para evitar interferências externas nas suas decisões, ao contrário, leva-o para uma competição com as máquinas, renunciando, gradativamente, à sua subjetividade para se adaptar aos mecanismos de dominação da sociedade capitalista.
\end{abstract}

Palavras-Chave: Autonomia. Aperfeiçoamento técnico-operacional. Racionalidadetécnico-científica. Operador do saber técnico-científico.

\section{TOWARDS A DEBATE BETWEEN SUBJECTIVITY AND TECHNICAL- SCIENTIFIC THINKING IN DIALOGUE WITH ADORNO AND HORKHEIMER}

\begin{abstract}
:
This article considers the issue of subjectivity and technical-scientific knowledge from the perspective of Theodor W. Adorno (1903-1969) and Max Horkheimer (1895-1973), above all, in the text Dialectic of Enlightenment (1985), with the objective to identify, based on the critique of Kantian concept of enlightenment, whether it is possible to have the subject's autonomy, conserving technical-scientific knowledge as the only valid form of knowledge. The modus operandi of this knowledge, transmutes the thinking subject into a technical operator to produce merchandise in capitalist society, converting autonomy into technical-productive improvement. With this, men and machines are unified, both by the language of science and in the serial production of goods. The search for the effectiveness and usefulness of knowledge, instead of encouraging man to strive to make use of his understanding on his own, to avoid

1 Parte deste artigo foi extraída da tese de doutoramento, intitulada "A crítica da racionalidade técnicocientífica e a formação do sujeito autônomo em Adorno no contexto da sociedade capitalista", de Ermínio de Sousa Nascimento, sob a orientação do Prof. Dr. Eduardo Ferreira Chagas, defendida em 2018, no Programa de Pós-Graduação em Educação da Universidade Federal do Ceará - UFC, Fortaleza, Ceará.

2 Doutor em Educação pela Universidade Federal do Ceará - (UFC). Professor Adjunto do Curso de Filosofia da Universidade Estadual Vale do Acaraú - (UVA). Coordenador do Projeto de Extensão: Sebo Cultural Itinerante: o Ensino de Filosofia na sociedade tecnológica. Membro do Grupo de Pesquisa Kant e Fichte: a Ressonância da Imaginação Transcendental na Estética Ilustrada. E-mail: herminionascimento@yahoo.com.br..

3 Doutor em Filosofia pela Universidade Federal do Ceará. Professor Adjunto da Graduação e da Pósgraduação em Filosofia da Universidade Estadual Vale do Acaraú - UVA. Líder do Grupo de Pesquisas Ludwig Feuerbach e Pensamento Pós-hegeliano (GPELF/ UVA-CNPq), membro pesquisador do Grupo de Pesquisa em Filosofia da Religião (GEPHIR/UVA-CNPq) e do Laboratório de Estudos Hegelianos (LEH/UVA-FUNCAP). E-mail: semedmar@yahoo.com.br.
\end{abstract}


external interference in his decisions, on the contrary, leads him to a competition with machines, renouncing , gradually, its subjectivity to adapt to the domination mechanisms of capitalist society.

Keywords: Autonomy. Technical-operational improvement. Technical-scientific rationality. Operator of technical-scientific knowledge.

\section{Introdução}

Neste artigo se objetiva avaliar até que ponto é possível haver a autonomia do sujeito, pensada em sentido kantiano, conservando-se o saber técnico-científico na sociedade burguesa, tendo por fundamento a concepção de subjetividade na perspectiva de Theodor W. Adorno (1903-1969) e Max Horkheimer (1895-1973), sobretudo na obra Dialética do esclarecimento (Dialektik der Aufklärung [1985]).

No primeiro momento da exposição, trata-se de discutir sobre o operador do saber técnico-científico, concebendo-o como uma espécie de "autoridade técnica". A sua habilidade consistiria primariamente no aperfeiçoamento técnico-operacional, para o que estaria apto à produção de mercadorias para abastecer as demandas de uma sociedade capitalista, e não de desenvolver uma formação compreendida no sentido de promover sua autonomia ou autogoverno.

Para complementar essa questão, busca-se expor, pelo recurso a certa "estrutura funcional da linguagem", o que Adorno e Horkheimer (1985) afirmam, a saber, que o saber técnico-científico se efetiva pela unidade entre homens e coisas que nulifica a subjetividade. $\mathrm{O}$ argumento é que aquilo que não se reduz a número, passa a ser ilusório para o saber científico, o que nos conduz ao problema da relação entre produção e subjetividade.

O último ponto que interessa à tematização do nosso problema é debater a unidade entre homens e máquinas que, sem a interferência de uma espécie de "subjetividade", torna o "saber" como que direcionado à simples (re)produção de mercadorias, promove uma concorrência entre os pólos em causa e a eficácia passa a assumir a posição de critério a seguir. A eficácia da produtividade, entretanto, talvez ponha as máquinas numa posição privilegiada em relação aos homens, uma vez que elas são programadas para a produção em série, mantendo a padronização da mercadoria. Isso exigirá dos indivíduos, além do simples aperfeiçoamento técnico-científico, um tipo de "esforço pessoal" para evitar que a sua subjetividade interfira na produtividade de artefatos padronizados pelas entidades que compõem a sociedade capitalista. A pergunta que se impõe é: até que ponto, nessa competitividade direta com as máquinas

\begin{tabular}{|c|c|c|c|c|}
\hline Revista Dialectus & Ano 9 & n. 17 & Maio - Agosto 2020 & p.96-111 \\
\hline
\end{tabular}


na linha de produção, o esforço individual dos homens para viverem na sociedade capitalista é direcionado para o autogoverno ${ }^{4}$ ?

\section{Sobre o "operador do saber técnico-científico"}

Considerando a filosofia de Adorno e Horkheimer (1985), pensar a subjetividade requer compreender o uso do saber técnico-científico para a produção de mercadorias na modernidade. $\mathrm{O}$ modus operandi da ciência moderna, com o recurso às máquinas no processo produtivo, promove uma transmutação do sujeito pensante em mero"operador do saber técnico-científico". Com isso significamos que o homem passa a ser concebido univocamente, em uma dimensão meramente operacional.O“saber"que é adquirido por ele parece permanecer restrito ao universo da produção de mercadorias no sistema capitalista, reduzindo a potência crítica do pensamento à mera constatação e reprodução irrefletida de fatos. Nesse caso, o pensamento que não for comprovado pelos fatos se configura como uma espécie de ilusão ou tautologia ${ }^{5}$, algo que implica que o pensamento sem comprovação empírica é concebido como vinculado a uma esfera lógico-metafísica que careceria de qualquer valor científico. Por isso, aí o pensamento é subjugado por uma série de procedimentos metodológicos e por uma linguagem matemática que, juntos, requerem unicamente a quantificação dos acontecimentos, não aceitando nada que não possa ser mensurado. Os conceitos filosóficos (metafísicos) ficam fora do alcance dessas ciências por falta de critérios, de um método que possa verificar a sua validade e sua verdade.

Pelo método ${ }^{6}$, o homem moderno controla a natureza sem recorrer a forças

\footnotetext{
${ }^{4} \mathrm{~A}$ noção de autogoverno vem aqui equiparada à conceituação kantiana de autonomia, tal como compreendida em Resposta à pergunta: que é Esclarecimento? (Beantwortung der Frage: Was ist Aufklärung? [1784]). Não é demais ressaltar que Kant, na obra considerada, trata da importância de que o sujeito empreenda a saída da menoridade, amparada na"comodidade"/"conveniência" (Bequemlichkeit), por um "esforço" (Bemühung), que leva à decisão (Entschließung) e coragem (Muthes) de "servir-se de si mesmo", para afastar-se da tutela seja por outros homens, seja por quaisquer entidades sobrenaturais. É essa compreensão de autonomia que serve de parâmetro para se avaliar, no presente trabalho, como o saber técnico-científico corrobora para a nulidade da subjetividade. A respeito do tema do esclarecimento kantiano e sua relação com a educação, cf. LIMA FILHO, 2019.

${ }^{5}$ Nas palavras da Dialética do Esclarecimento, "o factual tem a última palavra, o conhecimento restringe-se à sua repetição, o pensamento transforma-se em mera tautologia" (ADORNO; HORKHEIMER, 1985, p. 34).

${ }^{6} \mathrm{O}$ método científico, que levava sempre a uma dominação cada vez mais da natureza, proporcionou depois também os conceitos puros e os instrumentos para a dominação cada vez mais eficiente do homem sobre os homens, através da dominação da natureza ... Hoje, a dominação eterniza-se e
}

\begin{tabular}{|l|l|l|l|l|}
\hline Qovista Qialectus & Ano 9 & n. 17 & Maio - Agosto 2020 & p.96-111 \\
\hline
\end{tabular}


sobrenaturais para produzir o conhecimento: “[...] a matéria deve ser dominada sem o recurso [...] a forças sobrenaturais [...]. O que não se submete ao critério da calculabilidade e da utilidade torna-se suspeito para o esclarecimento" (ADORNO; HORKHEIMER, 1985, p. 19). Ao auxílio da linguagem matemática é adicionada a noção de utilidade, pois que o saber precisa ser útil para ter validade científica na modernidade. As experiências realizadas sobre a natureza, com o intuito de submetê-la às suas regras para obter resultados conforme hipótese levantada inicialmente, acabam, no entanto, por recair também sobre as pessoas em sociedade. Os indivíduos passam a ser modelados pelas regras próprias do capital, com o objetivo de fortalecer a manutenção da sociedade burguesa, e o comportamento humano é pensado sempre em função do sistema econômico, calculado previamente pela razão técnico-operacional, antes mesmo da fabricação de mercadoria a ser consumida por eles (Cf. ADORNO; HORKHEIMER, 1985). Tem-se, então, por um lado, um método científico que subjuga o pensamento ao fato, àquilo que acontece no mundo, e, por outro, o sistema capitalista que se conserva pelo lucro, tendo a sua eficácia concernida pela operacionalidade constituída pelo saber técnico-científico no indivíduo, que consta como seu aliado (Cf. NASCIMENTO; CHAGAS, 2016).

Ainda no século XVIII, Kant advertia para a importância de pensar o processo de esclarecimento como o necessário abandono da heteronomia em função de um aprimoramento moral que fizesse coincidir os interesses da educação com a autonomização do sujeito humano. Isso significava, para Kant, não apenas munir os sujeitos de certas "habilidades" operativas, se bem que importantes para o cultivo de si, senão também de orientar suas disposições naturais na direção de um crescente melhoramento humano, pelo qual ele pudesse tornar-se civilizado para o convívio social e, ao mesmo tempo, para que fosse capaz de abandonar toda forma de tutela que sobre ele se impõe, no sentido de atingir a qualidade da autonomia ou do que aqui conceituamos como autogoverno. Esse ideal de formação kantiano, em que se articulariam o aperfeiçoamento teórico e o melhoramento moral, não parece ter sido realizado na modernidade, pois que o saber técnico-científico parece produzir um distanciamento entre a capacidade operacional e o autogoverno.

amplia-se não só mediante a tecnologia, mas como tecnologia: e esta proporciona a grande legitimação ao poder político expansivo, que assume em si todas as esfera da cultura (MARCUSE Apud. HABERMAS, 1968, p. 49).

\begin{tabular}{|l|l|l|l|l|}
\hline Q Povista Dialectus & Ano 9 & n. 17 & Maio - Agosto 2020 & p.96-111 \\
\hline
\end{tabular}


Isso significa que precisamos considerar uma polissemia do conceito kantiano de autonomia para satisfazer aos nossos propósitos e nos aproximar de uma avaliação dos nossos tempos, com Adorno: a autonomia pode vir compreendida como autogoverno, embora igualmente possa ser tomada como certa autoridade técnica para fazer jus ao saber técnico-operacional, embora essas duas concepções de autonomia parecem ser conflitantes, uma vez que a primeira se efetiva pela superação de intervenções externas nas decisões do sujeito pensante; isto é, o autogoverno não se realiza enquanto as decisões dos indivíduos forem conduzidas pela interferência de tutores.

Tais interferências ainda se fazem presentes no contexto do saber técnicocientífico, na sociedade capitalista: “[...] as pessoas aceitam com maior ou menor resistência aquilo que a existência dominante apresenta à sua vista [...] lhe inculcando à força, como se aquilo que existe precisasse existir dessa forma" (ADORNO, 1995, p. 178). Apesar de haver uma diferença de aproximadamente dois séculos entre as afirmações de Adorno e Kant, é possível inferir que a autonomia, como autogoverno previsto por Kant, ainda não se efetivou, segundo o diagnóstico de Adorno. Com a predominância do saber técnico-científico na modernidade, parece que o máximo que se atingiu seja coincidente com a efetivação de um tipo de“autoridade técnica", reconhecida pela capacidade de um sujeito para produzir mercadorias na sociedade capitalista. A autoridade técnica é, então, sinônimo de saber fazer algo. Com isso se concebe o homem de ciência como aquele que "[...] conhece as coisas na medida em que pode fazê-las" (ADORNO; HORKHEIMER, 1985, p. 21).

Tal autoridade, diferentemente da autonomia como autogoverno, tem a sua capacidade de tomar decisão pautada em um modelo procedimental técnicooperacional, que nulifica a subjetividade individual das pessoas em nome do fabricar seriado ou da produção em escala. As diferenças individuais são eliminadas para reconhecer tudo como idêntico, de modo que "[...] aquilo que não se reduz a números e, por fim, ao uno, passa a ser ilusão" (ADORNO; HORKHEIMER, 1985, p. 23). Humanos e coisas acabam por formar uma unidade e, por isso, são vistos como quantidades mensuráveis, submetidos ao procedimento operacional eficaz; o limite desse contexto consiste em que a busca pela verdade seja, por fim, substituída pela eficácia da produtividade.

\begin{tabular}{|l|l|l|l|l|}
\hline Qovista Dialectus & Ano 9 & n. 17 & Maio - Agosto 2020 & p.96-111 \\
\hline
\end{tabular}




\section{Nulidade da subjetividade e linguagem}

No processo de aperfeiçoamento técnico, as máquinas deixam de ser vistas apenas com artefatos mecânicos e tecnológicos e passam a ser admiradas como algo que está acima do homem e como algo a imitar, sobretudo quanto ao ritmo de produtividade e de eficácia (Cf. MATOS, 1993). Nesse processo, a aquisição do conhecimento não é garantia de autonomia do sujeito, pois ele não está a serviço da humanidade para preservar a vida das pessoas, mas em função da classe dominante, da economia burguesa. O pensamento, que passa a se objetivar na forma da linguagem matematizada, torna-se reificado: "o pensar reifica-se num processo automático e autônomo emulando a máquina que ele próprio produz para que ela possa finalmente substituí-lo" (ADORNO; HORKHEIMER, 1985, p. 33).

O que Adorno constata é como que haja uma transmutação da autonomia do sujeito, no sentido kantiano, para o agente operacional que projeta a linguagem matemática sobre o mundo. Como essa linguagem funciona é algo que escapa à Dialética do Esclarecimento; mas é possível que a compreensão de linguagem referencial analisada, sobretudo, por Ludwig Wittgenstein (1889-1951), no Tractatus Logico-Philosophicus (1984), possa nos auxiliar na elucidação de pelo menos uma porção daquilo que Adorno e Horkheimer concebem como linguagem matemática ou linguagem da ciência positiva.

Considerando a linguagem na sua estrutura funcional, tem-se uma parte fixa, denominada de predicado, e um lugar vazio, chamado de variável proposicional (Cf. LIMA FILHO; NASCIMENTO, 2008). Como exemplos, pode-se dizer que " $\mathrm{x}$ é ser vivo" ou "x é fenômeno", em que"x" é a parte variável que pode ser substituída por qualquer nome para gerar uma sentença declarativa (Satz) dotada de possível valor de verdade, ou seja, que possa ser verdadeira ou falsa. No caso das sentenças enunciativas verdadeiras, as que interessam às ciências, o "x", no primeiro exemplo, pode ser substituído por qualquer nome que designe objetos que são seres vivos - seres instanciados entre os animais e os vegetais -, algo que vai gerar a sua verdade. Tais objetos são unificados no predicado: _ é ser vivo. As suas diferenças são eliminadas (Cf. SANTOS, 1994). De forma análoga pode-se proceder com o segundo exemplo e com outros casos similares - não é demais lembrar que homens e coisas se unificam nesta linguagem.

\begin{tabular}{|l|l|l|l|l|}
\hline Qovista Dialectus & Ano 9 & n. 17 & Maio - Agosto 2020 & p.96-111 \\
\hline
\end{tabular}




\section{Ermínio de Sousa Nascimento/ José Edmar Lima Filho}

Nesse caso, temos de considerar a existência do ser humano como um operador da linguagem - aquele que usa as sentenças declarativas (Satz) para descrever os fatos -, sem negligenciar que o fato tem a última palavra e que o conhecimento se restringe a sua repetição (Cf. ADORNO; HORKHEIMER, 1985). Aqui, o operador parece projetar a linguagem sobre o mundo, direcionando as frases para os fatos, articulando cada nome na frase a cada objeto que compõe o fato ${ }^{7}$. É o ato em que "[...] o nome substitui, na proposição, o objeto" (WITTGENSTEIN, 1994, § 3.22), que ocorre no fato. Esse modo de proceder do operador da linguagem iguala o sujeito pensante às máquinas programadas para realizar funções. A estrutura geral para a efetivação do pensamento pressupõe (i) um mundo onde os fatos ocorram, (ii) uma linguagem que os descreva e (iii) um operador para conduzir a linguagem até aos fatos, ou seja, um operador das regras semânticas. O mecanismo de funcionamento dessa estrutura pode ser representados ${ }^{8}$ pelos gráficos abaixo. Tomando como exemplos os que se seguem:

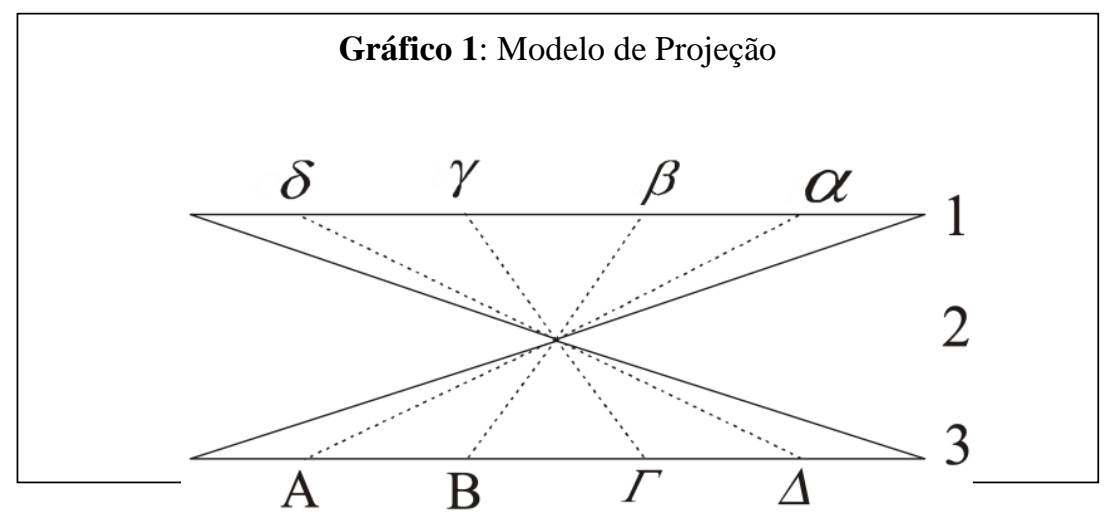

Fonte:GRIFFIN, J. Wittgenstein's Logical Atomism. Londres/Seattle: University of Washington Press, 1969, p. 129 - adaptado.

Esse primeiro gráfico se compõe de três níveis: o primeiro, marcado com letras gregas minúsculas, representa a possibilidade de existência de objetos no mundo.

\footnotetext{
${ }^{7}$ Ao interpretar a abordagem wittgensteiniana sobre "o que é pensar" no Tractatus logicophilosophicus, Nascimento afirma que: "a expressão dos pensamentos se limita a linguagem que figura o mundo. [...] pensar equivale a pensar o sentido de uma frase declarativa (Satz), em que algum estado de coisas(situaçõespossíveis) é projetado no espaço lógico. O sentido da frase determina a relação projetiva envolvendo, de um lado, os nomes na frase, e, de outro lado, os objetos no estado de coisas. Frases declarativas são formadas por nomes conectados um com o outro, numa cadeia, e igualmente os fatos são objetos conectados um com outro, numa cadeia; a totalidade das frases é a linguagem e a totalidade dos fatos é o mundo. Então pensar é o ato de projetar no espaço lógico o sentido de uma proposição elementar num estado de coisas, considerando cada nome na frase em relação a cada objeto no estado de coisas" (NASCIMENTO, 2006, p. 8). Tudo que estiver fora de tais condições é considerado como indizível, é mera ilusão.

${ }^{8}$ Os gráficos utilizados nesta secção são retirados de MARQUES, 1998e adaptados por NASCIMENTO, 2006.
}

\begin{tabular}{|l|l|l|l|l|}
\hline Qovista Dialectus & Ano 9 & n. 17 & Maio - Agosto 2020 & p.96-111 \\
\hline
\end{tabular}


No terceiro, as letras maiúsculas representam a existência de nomes que compõem a linguagem. O nível dois contém o sujeito pensante ou o operador da linguagem que tem como função projetar os elementos do nível três para os elementos do nível um. Nesse procedimento, a condição para a efetivação do pensamento consiste em fazer com que cada nome do nível três se conecte em cada objeto do nível um. O sujeito realiza essa operação para dizer o que acontece no mundo, mas o significado dos nomes e o sentido da frase não é tarefa sua realizá-lo. No caso dos nomes, os objetos nomeados por eles asseguram os seus significados, não dependendo da interferência do sujeito. Já o sentido da frase se efetiva pelo ato de descrever os fatos, levando em consideração o significado de cada nome que a compõe.

Um segundo gráfico, composto por um Centro de Projeção, representado por $\mathrm{O}$, o sujeito pensante como“operador da linguagem”; os nomes são os raios $\alpha, \beta, \gamma \mathrm{e}$ os objetos são representados pelas letras A, B, C:

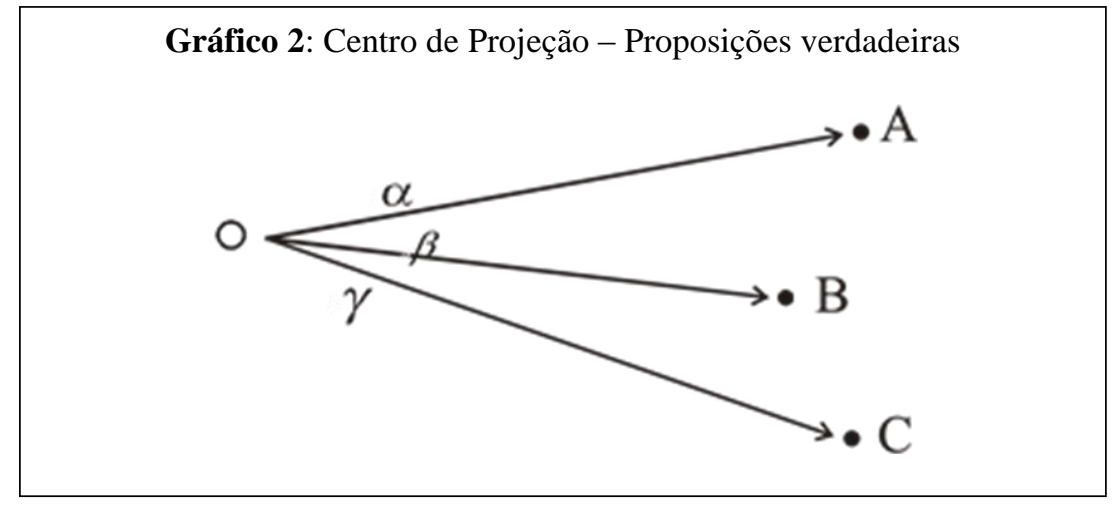

Fonte: SHWAYDER, D. On the Picture Theory of Language: Excerpts from a Review. In. COPI, I., BERARD, R. W. (Org.) Essays on Wittgenstein's Tractatus.Nova York: Hafner, 1973, p. 312 - adaptado.

Nesse segundo gráfico, nota-se que o“operador da linguagem” verifica se as condições de verdade, estipuladas pelo método científico, são satisfeitas no gráfico: se aquilo que a ciência exige para uma afirmação ser verdadeira foi atendido no ato de projetar os nomes sobre os objetos que compõem os fatos descritos. No caso do gráfico acima, pelo fato de todos os raios dos nomes $\alpha, \beta, \gamma$, que partem do centro de projeção O, tocar diretamente os objetos A, B, C, ou seja, por haver uma coincidência entre cada um dos raios com cada um dos objetos, as condições de verdade foram satisfeitas. Por isto, a projeção da proposição que tem aquela configuração é verdadeira. A falsidade da

\begin{tabular}{|l|l|l|l|l|}
\hline Qovista Dialectus & Ano 9 & n. 17 & Maio - Agosto 2020 & p.96-111 \\
\hline
\end{tabular}


projeção aconteceria em algo similar ao gráfico seguinte:

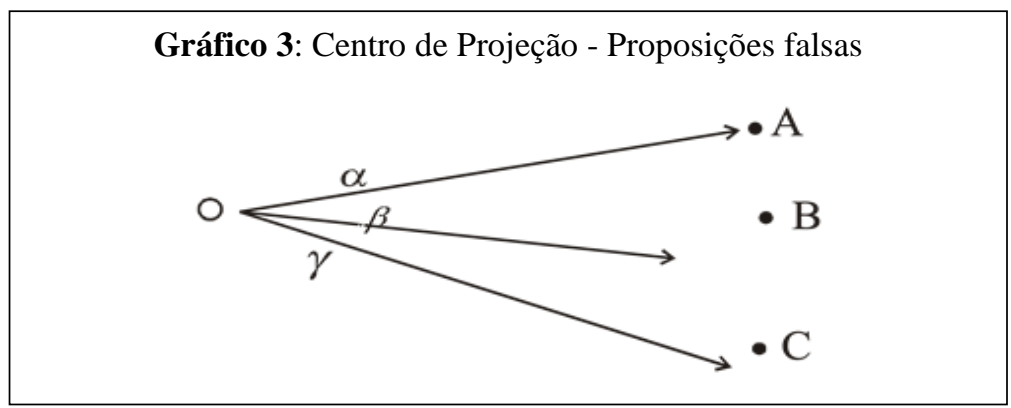

Fonte: SHWAYDER, D. On the Picture Theory of Language: Excerpts from a Review. In. COPI, I., BERARD, R. W. (Org.) Essays on Wittgenstein's Tractatus. Nova York: Hafner, 1973, p. 312 - adaptado.

Nesse caso, os raios $\beta, \gamma$, que partem do centro da projeção não tocam os objetos $\mathrm{B}, \mathrm{C}$, ou seja, os nomes $\beta, \gamma$, não coincidem com nenhum objeto na projeção. Pela ausência de coincidência entre ambos tem-se a falsidade da frase projetada da linguagem sobre o fato.

Nota-se, portanto, pelo uso dos gráficos acima uma ilustração do aspecto procedimental-operacional que se efetiva pelo engessamento do pensamento do sujeito. Ele é instrumentalizado para exercer determinadas funções específicas na sociedade. E como a sociedade burguesa se fortalece pela desigualdade social, pela exploração do homem por outro homem, o operador da linguagem também exerce a função de operar o mecanismo de dominação instituído pelo capitalista. Fazendo uso da razão instrumental, a classe burguesa define o que é útil e direciona a operacionalidade para a sua consolidação. O que é útil para o dominante passa a ser útil para o trabalhador. $\mathrm{O}$ interesse do dominante se sobrepõe à liberdade dos indivíduos em nome da realização de ações que assegurem a autoconservação do sistema capitalista.

Como descrito, no processo de exploração do outro, o capitalista acaba por unificar homens e máquinas; o criador e sua criatura são usados na manutenção de um modelo de sociabilidade que permanece dividido em classes opostas, de tal modo que eles concorrem entre si enquanto buscam um espaço na produção de mercadorias. Nessa concorrência, a atenção do homem não é sobre a sua condição de dominado pelo capitalista, mas sobre o seu oponente na linha de produção - a máquina. O saber técnico-científico, portanto, não conduz o homem a perceber o problema da dominação na sociedade, senão que o torna refém de sua criatura. Há um desvio do que é real para o que é conveniente a quem detém o poder, promovendo nos indivíduos o medo de

\begin{tabular}{|l|l|l|l|l|}
\hline Qovista Dialectus & Ano 9 & n. 17 & Maio - Agosto 2020 & p.96-111 \\
\hline
\end{tabular}


serem superados pelas máquinas e os levando a se "comportar” tal como elas.

\section{Sobre a produção de mercadorias}

No cenário avaliado por Adorno e Horkheimer, homem e máquina são vistos como meios de produção. O capitalista incentiva a concorrência entre ambos, mas são as máquinas que ditam o ritmo da produtividade, pois que elas são programadas para produzir em série com eficácia. $\mathrm{O}$ critério de padronização das mercadorias é um fator crucial para a instituição do império das máquinas no mercado de trabalho a partir da revolução industrial, no século XIX, e no avanço do progresso tecnológico na contemporaneidade. Os produtos padronizados contribuem para a substituição do "sujeito pensante" pelo "operador do saber", pois o uso da imaginação ou da reflexão podem interferir na configuração do produto, desviando-o daquilo que foi estabelecido previamente pelo capitalista para atender a uma demanda específica de mercado. Assim, para competir com as máquinas no mundo do trabalho, o homem substitui a reflexão pela mera habilidade de operacionalização: o saber técnico-científico se sobrepõe à subjetividade individual, ajustando o seu comportamento à dimensão operacional.

Comparando esta questão com a estrutura matemática da linguagem, vamos tomar como exemplo a sentença declarativa "x trabalha". Para que esta variável seja capaz de formar uma frase verdadeira, pode-se substituir o " $\mathrm{x}$ " ou por indivíduos considerados humanos ou por máquinas. Nos dois casos, homens e máquinas se unificam pela capacidade de trabalhar. Assim como na ciência o sujeito pensante se converte em operador da linguagem (como anunciado no gráfico 1), sem a reflexão do sujeito, por analogia tem-se o trabalhador como o operador de conhecimentos técnicocientíficos no mundo do trabalho. Pondo o trabalhador no centro de projeção, independentemente de ser homem ou máquina, a sua função é operar o saber técnicocientífico para fazer coisas. O capitalista define o ritmo e a padronização do produto para gerar o lucro esperado. Esses seriam os critérios para o trabalhador ser admitido no mercado de trabalho.

Aplicando o modelo de projeção dos gráficos 2 e 3 sobre o operador do saber técnico-científico, e substituindo à noção de verdade pelos critérios de produtividade do sistema capitalista, temos que o trabalhador humano ou a máquina ocupam a posição $\mathrm{O}$ do centro de projeção, projetando o saber técnico-científico sobre a

\begin{tabular}{|l|l|l|l|l|}
\hline Revista Dialectus & Ano 9 & n. 17 & Maio - Agosto 2020 & p.96-111 \\
\hline
\end{tabular}


produção de mercadorias. A sua eficácia se efetiva quando gera o lucro esperado pelo capitalista. Essa projeção equivale à verdade da projeção do gráfico 2. Quando isso não acontece, tem-se a ineficiência da projeção que é representada pelo gráfico 3. A validade do saber científico se converte em eficiência do trabalhador no sistema capitalista.

Nesse esquema de raciocínio, o sistema capitalista elabora as condições a serem atendidas pelo trabalhador para a efetivação da eficácia da produtividade. A produtividade está associada a metas a serem alcançadas pelos trabalhadores, que potencializam os lucros do capitalista para a conservação do sistema. É neste contexto que os homens competem seja com as máquinas, seja com os outros homens: os indivíduos são levados a renunciar à reflexão sobre a realidade para se aperfeiçoar tecnicamente. É nesse sentido que Marcuse argumenta que

\begin{abstract}
a máquina tornou-se antes um elemento de um sistema organizacional que, por sua vez, determina as formas de comportamento do trabalhador, não só dentro de cada empresa, como também em todas as esferas da existência. A exigência de energia técnico-psíquica, em vez de energia física, equipa o trabalho no processo de produção material [...] No interior desse aparato definido pelas máquinas [...] o trabalhador vive num todo que aparentemente se automovimenta, mecanizado e rotineiro, que faz vibrar consigo. As máquinas e as formas de comportamento imposta pelas máquinas movem-se, no sentido literal, comunicando-lhe seu ritmo - não só no trabalho mas também durante o tempo livre, nas férias, ao andar. [...] neste novo ritmo, proveniente do trabalho mecanizado e automatizado, a alma do trabalhador é igualmente mobilizada (MARCUSE, 1999, p. 52-53).
\end{abstract}

O homem é, então, assimilado como um simples instrumento, cujo objetivo está delimitado por exercer funções previamente determinadas pela sociedade burguesa, ignorando a condição de dominação imposta por ela. Por esse motivo é que a racionalidade de dominação na modernidade se efetiva pela associação das forças produtivas ao progresso técnico-científico, como sugere Habermas: “A racionalidade da dominação mede-se pela manutenção de um sistema que pode permitir-se converter em fundamento da sua legitimação o incremento das forças produtivas associada ao progresso técnico-científico" (HABERMAS, 1968, p. 47). A dominação passa pelo processo de aumento da produtividade de bens materiais, da expansão do domínio do homem sobre a natureza e a sensação de uma vida mais confortável que essa racionalidade proporciona aos indivíduos (Cf. HABERMAS, 1968).

O pensamento abstrato que outrora orientava a produção do conhecimento e as ações do homem, agora, no sistema capitalista, é sobreposto pelo ritmo e rito do trabalho seriado, e a capacidade de produzir mercadoria se superpõe à "capacidade do

\begin{tabular}{|l|l|l|l|l|}
\hline Q Povista Dialectus & Ano 9 & n. 17 & Maio - Agosto 2020 & p.96-111 \\
\hline
\end{tabular}


pensamento autônomo" dos indivíduos. Isso significa, que o contexto do capital faz que as ações humanas permaneçam controladas e avaliadas perenemente pela técnica, não sem destacar que esse controle técnico seja intolerante com o que transcende o mundo dos fatos, objetivamente constituídos. A realidade subjetiva perde força em função de seu caráter crítico, especulativo, em prol da "racionalização operativa" da realidade objetiva.

Há muitos desdobramentos desse avolumamento do pensamento operativo, mas talvez um dos mais significativos consista no fato de que a liberdade do sujeito seja gradualmente substituída pela eficácia no desempenho de atividades atribuídas a ele, favorecendo um empobrecimento da autonomia do sujeito. O saber técnico-operacional transforma o indivíduo em um tipo de instrumento que serve de medium de uso na sociedade capitalista. Trata-se, portanto, do triunfo da operacionalidade sobre a capacidade crítica de pensar e agir do homem, de tal maneira que aquilo que seria a promessa de evolução e aprimoramento humano previstos pela racionalidade moderna acabou por se converter no seu oposto: no seu empobrecimento, na sua redução a procedimentos técnico-instrumentais (Cf. BICCA, 1997). Daí a constatação de Marcuse, para quem

[...] a liberdade anterior do sujeito econômico foi gradualmente submersa na eficácia com a qual ele desempenhava serviços a ele atribuídos. O mundo tinha se racionalizado a tal ponto, e esta racionalidade se tornou tal poder social, que o indivíduo não poderia fazer nada melhor do que adaptar-se sem reservas (MARCUSE, 1999, p. 78).

O prevalecimento dessa racionalidade na modernidade se justifica pelo seu serviço prestado às demandas criadas pela sociedade burguesa, tendo o mercado de trabalho como incentivo para a adesão dos homens a determinada área do saber. Tudo converge para o sistema capitalista, fato que conduz o homem a deixar de se preocupar em refletir sobre a relevância do saber científico para a vida em sociedade, para se adaptar ao ritmo de produtividade. Na proporção em que o homem se insere nesse ritmo, na produção de mercadorias ele finda por produzir a si mesmo, de maneira a se qualificar como mais uma mercadoria a ser posta à venda em um tal "mercado de trabalho". A sua satisfação se manifesta pelo índice de aceitação de sua qualificação profissional no mercado de consumo, a sua formação se converte em mercadoria para competir nas relações de troca no mundo capitalista e o indivíduo finda equivalendo-se à mercadoria, produzindo-a e sendo consumido.

\begin{tabular}{|l|l|l|l|l|}
\hline Q Rovista Dialectus & Ano 9 & n. 17 & Maio - Agosto 2020 & p.96-111 \\
\hline
\end{tabular}


Ermínio de Sousa Nascimento/ José Edmar Lima Filho

Nesse contexto, é previsível que a exploração e a opressão sejam naturalizadas. Os indivíduos são massificados e permanecem sem condição de reagir, de resistir, à condição de dominação em que se encontram. O homem de ciência, aquele que é "formado"exclusivamente para produzir mercadorias, o trabalhador, não reflete criticamente sobre a lógica do capital, senão que apenas busca se inserir no "sistema" para sobreviver, buscando algum grau de satisfação individual na tentativa de alcançar "ser bem-sucedido". Marcuse, contudo, ressalta que "ser bem-sucedido é o mesmo que adaptar-se ao aparato, não há lugar para a autonomia. Não há espaço para o protesto. [...] o indivíduo que persistisse em liberdade de ação seria considerado excêntrico" (MARCUSE, 1999, p. 52-53). Daí que, a consequência disso é que os indivíduos percam as suas individualidades para satisfazer a lógica do capital, qual seja, gerar lucro para o capitalista. A capacidade de tomar decisões por conta própria se converte em adaptação às regras da sociedade burguesa.

\section{Considerações finais}

Frente ao exposto, temos que a apropriação do saber técnico-científico pelo indivíduo, apesar de ser relevante para a sua inserção no mercado de trabalho, para o aumento da riqueza universal, ainda não é suficiente para promover a sua autonomia. A ciência na modernidade, com o advento da Revolução Industrial, converteu-se em força produtiva a serviço do capital (Cf. MARX, 1983). A riqueza do capitalista se efetiva às custas da pobreza do trabalhador. $\mathrm{O}$ aumento da produtividade, da riqueza universal, potencializado pelo uso da ciência e da tecnologia não se converte em redução da desigualdade social, senão que, ao contrário, assegura o lucro dos detentores dos meios de produção às expensas da exploração do trabalhador. Daí que o “[...] desenvolvimento da ciência, [...] não é mais que um aspecto e uma forma do desenvolvimento das forças produtivas humanas, isto é, da riqueza" (MARX, 1983, p. 38).

Para a força de trabalho se tornar uma mercadoria atrativa para o capitalista, ser funcional e assegurar o lucro almejado por ele, requer-se a apropriação do saber técnico-científico por parte dos indivíduos. Este saber os qualifica profissionalmente para assegurar a manutenção do sistema capitalista. Nele, a vida é concebida a partir dos interesses do sistema, de modo que aquilo que contribui para a sua manutenção, sem ameaças, converte-se em interesse também de cada pessoa. Os indivíduos são

\begin{tabular}{|l|l|l|l|l|}
\hline Qovista Dialectus & Ano 9 & n. 17 & Maio - Agosto 2020 & p.96-111 \\
\hline
\end{tabular}


remodelados pelos interesses, por vezes vendidos como feéricos, da sociedade burguesa, e, por isso, cada um, isoladamente, busca se realizar profissionalmente no interior deste sistema.

Com o progresso tecnológico e as suas influências na vida das pessoas em sociedade, pode-se perguntar se o homem que atua na sociedade capitalista é humano ou uma máquina, um robô, pois, ainda que este homem faça uso de sua inteligência para realizar certas abstrações impostas pela sua atividade laboral, ele se configura como um simples "operador de conhecimento": a inteligência humana se unifica com certa “inteligência artificial” das máquinas pelo fato de que o seu pensar se converte em simplesmente "operar" a linguagem das ciências em direção aos fatos, e o trabalho se efetiva pela operação do saber técnico-científico na produção de mercadoria.

Nesse sentido, a técnica passa a ocupar um lugar decisivo na vida das pessoas. Por um lado, isso pode contribuir de forma relevante para a vida humana, para amplificar as possibilidades de uma vinda cada vez mais longa e confortável; mas, por outro, o que prevaleceu na sociedade capitalista, o que é considerado como racionalidade boa, converte-se em irracionalidade, na medida em que a técnica passa a ser vista como tendo um fim em si mesma, deixando de ser uma "extensão do braço do homem" que realiza ações que contribuem para a autoconservação da espécie humana, para ser fetichizada na forma de mercadoria, desconectada da consciência das pessoas no seio da sociedade. Este é o império do homem tecnológico, afinado com a técnica, que se instrumentaliza pela razão para conservar o sistema capitalista em detrimento de sua autoconservação e a da humanidade (Cf. ADORNO, 1995).

O que interessa nesse cenário é que o fazer humano se converte em mera produção de mercadorias; a sua formação é para fazer coisas. Nesse sentido, o próprio homem se constitui como coisa, faz a si mesmo como mercadoria. Esse é o homem da ciência moderna, denunciado por Adorno e Horkheimer. A exemplo disso, pode-se evocar o operador do saber técnico-científico que foi contratado para projetar e executar o sistema ferroviário para conduzir as pessoas, vítimas do Nazismo, na primeira metade do século XX, até os campos de extermínios de Auschwitz (Cf. ADORNO, 1995). O esforço - que para Kant era condição imprescindível para a saída do homem da menoridade - aqui ele é sinônimo de capacidade técnica: a pessoa se esforça não para pensar por conta própria, para se autogovernar, mas para se apropriar de mecanismos tecnológicos para realizar algo, independentemente dos impactos de sua efetivação

\begin{tabular}{|l|l|l|l|l|}
\hline Qevista Dialectus & Ano 9 & n. 17 & Maio - Agosto 2020 & p.96-111 \\
\hline
\end{tabular}


sobre a vida das pessoas.

No caso da execução da obra acima anunciada, o esforço realizado pelo operador do saber técnico-científico se contrapõe à autonomia do sujeito, nos moldes kantianos, para se efetivar como procedimento operacional, do que se constata que a autonomia técnica do homem prevaleceu sobre o autogoverno. O extermínio de milhões de pessoas nos campos de concentração, pelo regime nazista, parece não ser uma questão relevante a ser considerada na decisão do operador do saber. Esse fato justifica a forma irracional com que a razão instrumental se impõe sobre os homens: eles e as máquinas são unificados na condição de coisa, de modo que nessa sociedade tecnológica, o homem afinado com a técnica é guiado por um tipo de progresso que “[...] transforma a Razão em submissão aos fatos da vida e à capacidade dinâmica de produzir mais e maiores fatos do mesmo tipo de vida [...]” (MARCUSE, 1967, p. 31) sem, no entanto, se contrapor à estrutura social que mantém o homem como seu refém. É essa dimensão irracional da razão que orienta as decisões dos indivíduos na sociedade que promove a nulidade da subjetividade humana, fazendo prevalecer diversas formas de controle social da vida humana.

\section{Referências}

ADORNO, T. W. Educação e emancipação. Trad. Wolfgang Leo Maar. Rio de Janeiro: Paz e Terra, 1995.

; HORKHEIMER, M. Dialética do esclarecimento: fragmentos filosóficos. Trad. Guido Antônio de Almeida. Rio de Janeiro: Jorge Zahar, 1985.

BICCA, Luiz. Racionalidade moderna e subjetividade. São Paulo: Edições Loyola, 1997.

GRIFFIN, J. Wittgenstein's Logical Atomism. Londres/Seattle: University of Washington Press, 1969.

HABERMAS, J. Técnica e ciência como Ideologia. Trad. Artur Mourão. ed. 70, Lisboa, Biblioteca de Filosofia contemporânea, 1968.

KANT, I. "Resposta à pergunta: que é o Esclarecimento?” In: KANT, I. Textos Seletos (edição bilíngue). Trad. Raimundo Vier. 2 ed. Petrópolis: Vozes, 1985.

LIMA FILHO, J. E. Esclarecimento e Educação em Kant: a autonomia como projeto de melhoramento humano. Trans/Form/Ação, Marília, v. 42, n. 2, p. 59-84, Abr./Jun., 2019.

\begin{tabular}{|l|l|l|l|l|}
\hline Qevista Dialectus & Ano 9 & n. 17 & Maio - Agosto 2020 & p.96-111 \\
\hline
\end{tabular}


; NASCIMENTO, E. S. Linguagem e representação: uma abordagem

da Teoria da Figuração do Tractatus de Wittgenstein. Revista Homem, Espaçoe Tempo, v. 2, n. 1, p. 161-176, 2008.

MARCUSE, H. Ideologia da sociedade industrial. Trad. Giasone Rebuá. Rio de Janeiro, Jorge Zahar, 1967.

.Tecnologia, guerra e fascismo. Trad. Maria Cristina Vidal Borba. São Paulo, Unesp, 1999.

Cultura e sociedade. Vol. I. Trad. Wolfgang Leo Maar, Isabel Loureiro e Rosbespierre de Oliveira. Rio de Janeiro, Paz e Terra, 1997.

MARQUES, J. O. de A. Forma e Representação no Tractatus de Wittgenstein.São Paulo, Unicamp, 1998.

MARX, K. Os fundamentos da crítica da economia política. In: MARX, K.; ENGELS, F. Textos sobre educação e ensino. São Paulo: Moraes, 1983, p. 38-43.

MATOS, O. C. F. A Escola de Frankfurt: luzes e sombras do iluminismo. São Paulo: Moderna, 1993.

NASCIMENTO, E. de S. A crítica da racionalidade técnico-científica e a formação do sujeito autônomo em Adorno no contexto da sociedade capitalista. 2018. 136f. Tese (Doutorado) - Universidade Federal do Ceará, Programa de Pós-graduação em Educação, Fortaleza (CE), 2018.

O que é pensar para Wittgenstein no Tractatus logico-philosophicus. 2006. - Dissertação (Mestrado) - Universidade Federal da Paraíba, Programa de Pósgraduação em Filosofia, João Pessoa (PB), 2006.

CHAGAS, E. F. O homem no contexto da ciência moderna em Adorno e Horkheimer. In: CHAGAS, E. F.; ROQUE, J. I. B.; PEREIRA, A. M, dos S. (Orgs.). Filosofia da ciência e formação humana. Curitiba: CRV, 2016, p. 63-72.

SANTOS, L. H. L. dos. A essência da proposição e a essência do mundo. In: WITTGENSTEIN. Tractatus Logico-Philosophicus. São Paulo, EDUSP, 2 ed., 1994, p. 11-112.

SHWAYDER, D. S. On the Picture Theory of Language: Excerpts from a Review. In. COPI, I.; BERARD, R. W. (Org.) Essays on Wittgenstein's Tractatus. Nova York: Hafner, 1973, p. 305-312.

WITTGENSTEIN, L. Tractatus Logico-philosophicus. 2. ed.Trad. Luiz Henrique Lopes dos Santos. São Paulo, EDUSP, 1994.

\begin{tabular}{|l|l|l|l|l|}
\hline Qevista Dialectus & Ano 9 & n. 17 & Maio - Agosto 2020 & p.96-111 \\
\hline
\end{tabular}

